\title{
Research on the Dialectics in Architecture Design Idea
}

\author{
Feng Xiang \\ (School of Yibin Vocational and Technical college Yibin, Sichuan, China 576565007@qq.com)
}

\begin{abstract}
Based on the concept of the architecture theory and comment, this paper use the law of the modern architectural design. From the expression technique, creativity and inspiration, function and structure, and the future development trend of construction, etc., the architectural design realize the sustainable development of ecology, intelligent, and energy saving in the $21 \mathrm{st}$ century.

Keywords: Building Electric ; Creation and Creation Inspiration ; Creation Idea of Reverie

\section{INTRODUCTION}

In the history of human society, building vividly reflected the track of the development of human society and history, also contains the rich connotation of human society. It embodies the culture of human society. In today's era, with the changing of science and technology, new material, new technology, new technique of expression and application of new equipment to construction. People are not confined to use the standard of function, modeling, and proportion to examine the modern architecture. A lot of architects in architectural creation using the design language to express the heart sound, rhythm, and construction of the era of role in time. Therefore, the expression technique of the architecture design idea is arousing the people on the outlook for the future.
\end{abstract}

\section{THE TECHNIQUE EXPRESSION OF ARCHITECTURAL CREATION}

Style is the manner, style, method, rules, manners, style, and so on. The "law" of architectural creation two kinds of situations: one is able to express, such as all kinds of design rules, norms, function, and practicality. The second is not able to express, such as architecture, its depth is difficult to use language to say. Only the architecture of the designers and commentators to a certain state can think a good construction is good or bad. The content of the architectural expression is very rich. It includes entity, space, skills, working methods and thinking methods. Physical methods such as balanced, stable, proportion, scale, etc. The building shape is very exquisite, for example, the monument of Laibixi coalition in Germany is built to mark the event of defeated napoleon. And its size is failed. It do not match the actual size and imaginary size, thus to make people feel uncertain. Some body morphology can be simplified into a simple geometry. Such as the arc DE triomphe in Paris, can be simplified into the square, the diagonal intersection is the center of the circle arch. Why does it appear to be harmonious? But the final "harmony" need of architectural art accomplishment can comprehend. The person for the buildings, whether indoor or outdoor, is a problem of space. It can't look at the expression of construction technique in isolation, but should be comprehensive treatment. Architectural expressions show the symbol, metaphor, and also show the thought of Chinese philosophy system. It embodies the "nature and humanity," "people-oriented" in the process of the image model. Architectural thinking of Yin and Yang, which includes building the naturalness, order, dynamic, open, exclusive, fertile, consciousness, etc. Uses of the construction technique realize the dialectical unification of the building technology and the art.

\section{THE PROBLEMS IN THE CURRENT ARCHITECTURAL CREATION}

Architecture design is a process of logical thinking, image thinking, intuition thinking, inspiration thinking, system thinking and theoretical thinking. Therefore, we should fully aware of the creative work of architecture creation. Currently, there are the following problems of the construction creative work. Frist, the team is scattered, the society influence is not enough. Second, theory to guide practice is not good. Third, architecture criticism is an important way to develop the art of architecture, but it is not normal, in some places, the individual leadership is interferes, lead to the creation of the architectural art is difficult to occur the historic change. Forth, a lack of understanding of China's building system theory. Fifth, design personnel knowledge is aging; they are not to create as the guide, just to cater to individual leadership intention. Sixth, pays too much attention to the research of foreign architectural theory. Seventh, there are many misleading of celebrities and authority. Therefore, in order to unification of art and technology of architectural design, we must firmly grasp the problems existing in the architectural design in the new era. I use new theory, new ideas, new methods and new thinking dialectically to create a new space-time, which is unified of art and technology. 


\section{ARCHITECTURAL CREATION AND INSPIRATION}

Architectural creation and inspiration is an important content of architectural creation. Creation and inspiration are often considered exist at the same time. The inspiration is the most complicated and inspired spirit in human brain thinking. In the architectural creation, it is a prominent and innovation. But based on reality, in fact, it is innovation. It is a kind of coupling each related parameters of thinking together. It is a kind of communication. There is new thinking In the process of communication. It is a kind of encounter. There is new thinking and new technique in the relative chance coincidence.

\subsection{Structure Design}

Structure design is the important content of architectural creation. Since the human society, human beings have the most primitive living residence. First it is natural cave, then, in the practice activities of construction, human beings recognize that we can use the structure as a masking, in case of attack of wind and rain. The formation of structures is closely related to technical materials. In the creation, the labor instinctively make the architecture improve and landscaping. Paintings on the walls of the cave are performance of man's feelings, empathy in content and beautification content, which is the creation of original beauty architecture. With the development of the times, the progress of technology, the improvement of material, new technology, new materials, new equipment and the new construction method are produce. On the premise of meet the use function, the structure characteristics and the image and the spaces became one of creation and thinking of human beings. In modern architecture, the use of this new material is very important in the architectural creation.

\subsection{The Composition of the Functional Use}

For the purpose of use and suitable, the most basic requirements of architectural creation idea is as people's behavior needs space and reach the purpose of practical. Function concept is caused of the demand of human's life, work, and spiritual. It further is the performance of behavior and activity, and it is the requirements of space use.

The development of the society and the change of function are often forming the activity pattern of the whole society in a period of time. It must lead a relatively stable shape in the use of architectural technology, materials and art. This shape is the reaction of the characteristics chamber. Function concept not only in the plane, but also on the dimension and the spatial characteristics. For the purpose of practical, the function conception causes the ideas of the architectural design.

Function design, besides the use of the person also includes the adapt situation of natural environment to human body, such as cut off the noise, heat insulation. They are the new performance characteristics of building image.

\subsection{Image Design}

Human emotion performance reflected in building image. Emotional interests, hopes, miss, memorial constitute the overall emotional characteristics.

From religious, medieval religious church and Buddhist, Taoist temple, Taoist temple have its image characteristics. All of these spirit materialized contain certain meaning.

From the influence of the change of social and technological, as well as the feedback of the spiritual culture and the artistic performance, it is more outstanding performance for the image of the monuments.

\subsection{Space Design}

Every building has space and space feeling. Architectural creation idea is without the space research. Its scope, scale, scale, and the dimension size is conceived trigger factor. At the same time, the space conception is dependent on the structure. The structure is the support of the construction. The space conception is dependent on the use and function. Construction will ultimately meet the requirements of use. The space conception is dependent on the image. Because the image entity finally express the characteristics of the space, the most basic purpose is to achieve the unity of the idea, thinking.

\subsection{The Artistic Conception}

Artistic conception depends on the natural yearning and reproduce, for many of the phenomena, give people the aesthetic feeling. The art inspiration is a kind of representation and performance.

Artistic conception is inseparable with the buildings environment. Buildings are always exposed to natural and artificial environment is always affected by the environment. Therefore, the concept of the environment is always give requirements of building growth to people. The new building will spring out from a specific environment and want to get the best tacit understanding, harmony with environment. This harmony is not only the size and the image, but also the harmony and coordination obtained from ecological and physiological.

\section{DAYDREAM OF ARCHITECTURAL CREATION}

In the process of architecture creation, we should keep in mind the era mission, with a new idea to create a path of Chinese architectural creation. 


\subsection{The Change Trend of the Architectural Creation}

Because of the progress of the society, the development of science, technology innovation, the economic strength, the improvement of people's aesthetic view and the improvement of living standards, we should studied in all aspects in architectural design, in order to meet the new trend in human settlement environment.

\subsection{Reinforcement of Overall Consciousness}

The global consciousness of architectural creation should be strengthen, to realize the "urban-rural integration" of construction, the networked of city to villages, the concept of urban design. Pay attention to the information feedback of the urban development.

Under the Premise of the Knowledge Economy, it Increase the Technological Content.

a) The characteristics of the knowledge economy era

b) The strategy of sustainable development

c) Dematerialization of assets

d) Integration of the world economic

e) Better educated of economic decisions

To Solve the Problem of Creation, We Must Increase the Technology Content in the Knowledge Economy Era. Architecture design is a comprehensive and comprehensive. Strengthen the construction of urban green space, strictly control the "waste" emission standards, to make urban residents live in a comfortable, comfortable, healthy environment. Make full use of solar, wind, water, and make the building with the requirements of energy saving, healthy and sustainable development.

\subsection{The green building}

Make full use of sunlight, water, green land. Use top space to development vertical greening, adjust the temperature and humidity of the city, purify the air in cities, then let people live in a clean environment.

a) Sustainable development

b) The study of bionic architecture

c) The tendency of "clone" building

d) Increasing of cultural taste

e) The diversification of creation

f) The new material

g) Organic integration of architecture and nature.

h) Pay attention to the development of ecology, environmental protection, protection of water resources, protect the ecology.

i) The update of the aesthetic ideas, realize the iconic architecture creation, shaping an image, realize the leap.

j) Energy saving.

\section{Conclusion}

In all, the future architectural creation idea should have the diversity expression. It should realize the unification of the functional structure, the unity of the inspiration and creation, to create architecture of ecological, intelligent and sustainable development.

\section{References}

[1] Shen Fu-xi. Architectural Design Method [M]. Press of Tongji University.

[2] Zheng Chuan. Analyses of architectural space Expression[J]. Journal of Architecture. 1999(11). 